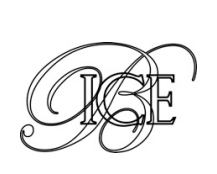

Francesc Granell Trias*

\title{
EL SISTEMA ECONÓMICO INTERNACIONAL EN 2013
}

La OCDE y el FMI que a mediados del 2013 habían revisado al alza las previsiones económicas del año volvieron a recortarlas a finales de noviembre vislumbrándose, esto sí, un 2014 algo mejor que el 2013 pero con elevado desempleo en Occidente y menores expectativas en los BRICS. La Abeeconomics japonesa empieza a dar crecimiento.

El euro parece definitivamente salvado tras las intervenciones del Banco Central Europeo, pero sigue la división entre países europeos centrales y periféricos de la eurozona respecto a continuar o no con las políticas de austeridad que llevan a protestas sociales. El endeudamiento global sigue creciendo y los EEUU y su dólar han sido atacados por China y Japón ante el temor de que sus bonos no puedan ser remunerados por los problemas presupuestarios de la Administración Obama.

La OMC ha desatascado mínimamente la Ronda de Doha en Bali pero no es el multilateralismo sino el regionalismo el que marca el comercio mundial.

Palabras clave: crisis económica mundial, mercados financieros, deuda externa, ayuda al desarrollo, Organización Mundial del Comercio, Fondo Monetario Internacional, Unión Europea.

Clasificación JEL: F02, F10, F13, F21, G15, E40, K33, L80, O10.

\section{Introducción}

La economía mundial sigue sin recuperar el pulso que perdió cuando estalló la crisis de las subprime norteamericanas en 2007 y cuando Greenspaan dejó caer a Lehman Brothers en septiembre de 2008 y aunque, en ciertos momentos, los organismos internacionales han mostrado un cierto optimismo con la aparición de «brotes verdes» en la economía mundial, como ha sido la salida de la -por dos años- recesión de los países europeos, el ligero crecimiento de Japón gracias a la Abeeconomics impulsada por su primer ministro Abe y los avances últimamente registrados en

* Catedrático de Organización Económica Internacional de la Universidad de Barcelona y miembro de número de la Real Academia de Ciencias Económicas y Financieras. Este artículo forma parte de la serie que con el mismo título viene publicando el autor en el Boletín Económico de ICE, por estas fechas, anualmente, desde 1977.

Versión de enero de 2014.
Estados Unidos pese a sus problemas de abismo fiscal -por el enfrentamiento entre la Administración Obama (que ha iniciado en 2013 su segundo mandato) y el Congreso respecto a frenar el gasto público y limitar el techo de deuda-, el menor crecimiento de China y los otros BRICS (Brasil, Rusia, India, China, Sudáfrica) y de algunos países latinoamericanos con fuertes caídas en su crecimiento (como es el caso de Venezuela) han connotado un entorno internacional de insuficiente desarrollo para ayudar a solucionar los problemas de deuda externa o de desempleo en que están muchas economías.

En este contexto de crecimiento no excesivamente brillante, en el artículo se repasa someramente lo que el 2013 ha dado de sí en cuanto a la coopeperación internacional en los planos comercial, monetario y de cooperación al desarrollo, para concluir asomándose a los avances que se han $D$ 
producido -con vacilaciones- en la integración europea y a las relaciones que España ha tenido con el sistema económico internacional en el segundo año del Gobierno monocolor de Mariano Rajoy.

\section{Las incertidumbres políticas y el sistema económico mundial}

De acuerdo con los análisis de finales de 2013, la economía mundial habrá crecido en el año que termina un 2,9 por 100, cifra algo inferior al 3 por 100 que se registró en 2012 y cifra algo inferior al desarrollo mundial en 2014 que se espera alcance el 3,6 por 100 gracias, sobre todo, a que Estados Unidos (que está creciendo ahora al 4,6 por 100 mientras que a mediados de año lo hacía al 2,8 por 100) va a volver a convertirse en la locomotora mundial por encima de lo que hasta 2012 había sido China. También Japón, pese a las vacilaciones de su economía, ha entrado en una nueva, aunque moderada, tasa de crecimiento tras dos decenios de estancamiento, que va a permitirle aportar más que la India al crecimiento de la economía global.

Estamos en una etapa en la que los BRICS están perdiendo fuerza en su crecimiento en contra de lo que parecía en los últimos años y si Europa se va poco a poco recuperando (en el 2013 la eurozona crece al 0,5 por 100 y se espera crezca al 1,7 por 100 en 2014) tras haber pasado el peor momento de la crisis de deuda soberana en sus países periféricos, podremos ver cambios globales positivos para la economía mundial. Alemania -siempre en situación de superávit fiscal y comercial- debería jugar como locomotora ya que el nuevo Gobierno de Gran Coalición, entre conservadores de Merkel y socialistas, debería ser más sensible hacia políticas menos austeras y más en línea con la necesidad de combatir el desempleo y a la caída del Estado de bienestar que está dando lugar a actuaciones no siempre perfectamente democráticas en los países europeos menos dinámicos.
La cuestión de la creación de empleo, en una sociedad en la que los robots substituyen cada vez más al trabajo humano, se ha convertido en una auténtica obsesión dados los altos niveles de desempleo que se registran. El desempleo entre los jóvenes es especialmente grave si se tiene en cuenta, además, que el alto endeudamiento en el que están incurriendo muchos países para evitar el abandono brusco del Estado de bienestar va a condicionar que sean las jóvenes generaciones las que deban hacerse cargo de la deuda contraída por sus mayores.

Todos estos problemas económicos vienen, además, connotados por cuestiones políticas de alcance diverso como son las amenazas bélicas de Corea del Norte ya condenadas por Naciones Unidas (7 de marzo), la aparición de tensiones entre China (ahora presidida por Xi Jinping desde el 14 de marzo) y Japón por viejas rencillas heredadas de la Segunda Guerra Mundial y conflictos por la disputa sobre algunos islotes que amenazan una cierta carrera armamentista. En el caso de Irán se ha entrado en una fase de apaciguamiento en las tensiones sobre un eventual desarrollo nuclear tras la subida al poder de su nuevo y moderado presidente Hasan Rohani, pero se detectan tensiones derivadas de la presencia de Al Qaeda. En el caso de la Guerra Civil siria se han vivido momentos de fuerte tensión entre Rusia y los Estados Unidos respecto a que Al Assad se mantuviera o no en el poder tras su ataque con armas químicas a los rebeldes (21 de agosto) y que casi hizo fracasar la Cumbre del G20 de San Petesburgo ${ }^{1}$ por la amenaza de $\triangleright$

1 El G-20 está compuesto por los miembros del G-8 (Alemania, Canadà, Estados Unidos, Francia, Gran Bretaña, Italia, Japón, Rusia y la Unión Europea), once países sistémicamente importantes (Arabia Saudita, Argentina, Australia, Brasil, Corea del Sur, China, India, Indonesia, México, Sudáfrica y Turquía). España asiste como observador permanente. A sus reuniones acuden el director gerente del Fondo Monetario Internacional, el presidente del Banco Mundial, el secretario general de las Naciones Unidas, el director general de la Organización Mundial de Comercio y el secretario general de la OCDE así como otros invitados representantes de Estados y de organismos. Además de reuniones de sherpas y de ministros sectoriales, el G20 ha celebrado, hasta el presente, cumbres en Washington (noviembre 2008), Londres (abril 2009), Pittsburg (noviembre 2009), Toronto (junio 2010), Seúl (noviembre 2010), Cannes (noviembre 2011), Los Cabos (junio 2012) y San Petesburgo (septiembre 2013). 
Obama de intervenir militarmente contra Al Assad y la posición finalmente triunfadora de Rusia de no hacerlo (5 de septiembre). Algunos quieren ver en este episodio y en la fuerza con la que Putin ha evitado la firma del acuerdo de Ucrania con la UE, una recuperación de Rusia en la arena mundial.

El 2013 tampoco ha permitido serenar el Mediterráneo de las revueltas árabes. En Libia se ha entrado en una desgobernanza tras la caída de el Gadafi y en Egipto el ejército ha destituido a Morsi, ganador de las elecciones, ilegalizando a los Hermanos Musulmanes al tiempo que hasta en Turquía (a otro nivel) el Gobierno islamista moderado de Erdogan está sometido a fuertes tensiones a parte de los laicos que desean el retorno al espíritu de Ataturk para poder aproximarse a la occidentalización por la que avanzaba Turquía hasta la últimas elecciones. Pese a estas tensiones en el Mare Nostrum, debe decirse que la Unión para el Mediterráneo continúa siendo -desde su Secretariado en Barcelona- la única plataforma en que los países mediterráneos y la UE se entienden y dialogan para la realización de proyectos en común que incluyen colaboraciones entre Israel, los países árabes y Palestina (Granell, 2013).

Al margen de estas tensiones políticas, de la sorprendente evolución de Venezuela tras la muerte del presidente Chávez y el acceso al poder semiabsoluto de Maduro y de las guerras religiosas y raciales en África Central y en Sudán del Sur, el 2013 ha visto una declaración sorprendente del Rey Guillermo de Holanda que en la apertura del año parlamentario (10 de septiembre) dejó caer la idea de que el Estado de bienestar está acabándose y que deberá ser sustituido por una sociedad participativa. En unos momentos en que el mundo se debate entre quienes consideran que el Estado controla demasiada parte del PIB y que ello va a ir a más por los problemas sociales, el endeudamiento público al alza, el desempleo elevado, las migraciones masivas y el envejecimiento de la población, las palabras del mo- narca holandés constituyen una auténtica declaración de principios que habrá que ver el seguimiento que pueda ir teniendo en los países avanzados y en las estrategias recomendadas por los organismos internacionales.

El sistema económico internacional -cada vez con más intensas interdependencias positivas y negativas- sigue necesitado de mecanismos efectivos de gobernanza mundial acordes con la necesidad de maximizar los bienes públicos globales y minimizar los males públicos globales derivados de los ciclos económicos, guerras comerciales y de divisas, paraísos fiscales, disfunciones nacionalistas, crimen organizado y otras cuestiones.

\section{El sistema comercial mundial y las integraciones regionales}

El comercio mundial que en el 2011 creció al 5 por 100 y que lo hizo al 3,7 por 100 en 2012, solamente lo ha hecho al 2,5 por 100 en el 2013 esperándose, esto sí, una recuperación hasta el 4,5 por 100 para el 2014. Este es un crecimiento que sería más propicio para los países que confían en la exportación para la recuperación de sus respectivas economías. Piénsese, a este respecto, que las exportaciones al mundo de los ahora cuatro países de la Comunidad Andina han caído en el 2013 en un 4 por 100, las de los 5 países del Mercado Común Centroamericano en un 2 por 100 y las del Mercosur en un 1 por 100.

La OCDE y la OMC han iniciado este año un análisis en profundidad de los flujos de comercio mundial según los valores añadidos para cada uno de los diferentes países. La acentuada interdependencia y los bajos niveles arancelarios hacen que las empresas, sobre todo las multinacionales, fabriquen en sus diferentes plantas con inputs procedentes de varios países y con ello la «exportación neta» difiere de las cifras globales hasta ahora manejadas. Con estos nuevos cálculos China ha dejado de ser el principal exportador mundial por el alto componente de importaciones que incorpora a $\triangleright$ 
sus exportaciones estrella. Tanto el secretario general de la OCDE -el mexicano Gurría- como el nuevo director general de la OMC -el brasileño Acevedo (entrado en funciones el 1 de septiembre)- confían en este nuevo instrumento analítico para clarificar la realidad de las redes mundiales de exportación e importación de bienes y servicios ${ }^{2}$.

De acuerdo con lo pactado en el G20 en su reunión de los Cabos de 2012, el Órgano de Examen de Políticas Comerciales de la OMC está colaborando con la OCDE y con la Conferencia de las Naciones Unidas sobre Comercio y Desarrollo (UNCTAD) en la elaboración de un informe bianual conjunto respecto a prácticas proteccionistas y neoproteccionistas: demandas de acción de la UE contra las placas solares chinas o de Mittal Europe frente a las exportaciones de acero chino, demanda de Rusia a la OMC por las sanciones a empresas rusas por precios supuestamente bajos respecto a sus precios internos en sus exportaciones a Europa, etcétera.

Durante todo el 2013 se han ido multiplicando las uniones económicas regionales y los acuerdos comerciales bilaterales y plurilaterales (De Lombaerde y Söderbaum, 2013) ante la falta de avance del sistema multilateral de comercio debido al estancamiento de la Ronda de Doha lanzada en la 4. ${ }^{\text {a }}$ Conferencia Ministerial de la OMC celebrada en tal localidad en $2001^{3}$. Pese a este

\footnotetext{
2 Discurso de Angel Gurría en su ingreso en la Real Academia de Ciencias Económicas y Financieras, pronunciado en Barcelona en noviembre de 2012.

3 La Ronda de Doha es la novena de las rondas multilaterales desde la creación del GATT en 1947. Lanzada en 2001 tras el atentado de las Torres Gemelas de Nueva York, es la primera desde la creación de la OMC en la que además de la liberalización del comercio de mercancías impulsado por el acuerdo GATT (incluidos ahora los productos agrícolas), se abordan temas de servicios cubiertos por el acuerdo GATS y cuestiones de propiedad intelectual bajo el acuerdo ADPIC, cuestiones de facilitación del comercio reduciendo los costes de transacción, mejora de reglas de aplicación sobre los diferentes códigos comerciales y el trato especial y diferenciados de los países pobres. Aunque el proceso de la Ronda de Desarrollo de Doha no haya culminado por no haberse llegado al compromiso único establecido como regla para culminar Doha, no puede decirse que en estos años desde su inicio, en 2001, no se hayan ido produciendo avances respecto a la regulación en los diferentes frentes cubiertos por la OMC. En estos años desde que se iniciara la Ronda se han producido, además, incorporaciones de nuevos miembros a
}

evidente estancamiento en la Ronda de Doha, que era patente desde el July Package de 1 de agosto de 2004, la $9^{\text {a }}$ Reunión Ministerial de la OMC (Bali, 3-6 de diciembre) ha querido ser interpretada en clave optimista por los ligeros avances respecto al sistema multilateral en ella pactados y que se refieren a facilitación del comercio (sin que los Estados ricos se hayan comprometido a financiar las mejores administrativas e informáticas que para ello deben introducir los países pobres), stocks de productos para la seguridad alimentaria (exigencia de India) y facilidades para los países menos avanzados.

Por la falta de conclusión de la Ronda Multilateral de Doha, pese a los ligeros avances registrados en la Conferencia Ministerial de Bali, son muchos los países y grupos de países que han entrado en la dinámica de firmar o ampliar acuerdos de carácter regional bilateral. Estados Unidos y la UE se han mostrado activos en este terreno. La UE ha concretado zonas de libre comercio con el Mercado Común Centroamericano, con Perú ( 1 de marzo) y Colombia (1 de agosto), como residuos del intento de acuerdo UE-Grupo Andino inicialmente planeado, así como con Canadá (18 de octubre) y un acuerdo de asociación con Moldavia habiendo quedado en el limbo el acuerdo con Ucrania por las presiones de Putin de $D$

la OMC, se han mejorado ciertos mecanismos institucionales de la OMC y se han concretado reglas sobre algunos de los códigos de comportamiento actualmente en vigor. Además se ha llegado a acuerdos con vistas a la supresión de las subvenciones agrícolas y se han perfilado diferentes opciones para profundizar en el desmantelamiento progresivo de aranceles y trabas respecto a productos no agrícolas. Los Estados miembros se han autodisciplinado en temas de no discriminación en materia de servicios y de mayor respeto a la propiedad intelectual. En el plano puramente arancelario hay que tener en cuenta que los aranceles son ya muy bajos aún antes de concluir la Ronda de Doha. La media de todos los países es de 3,7 por 100 , la de los países desarrollados del 2,5 por 100 , la de los paises en desarrollo el 6,9 por 100 y la de los países menos avanzados del 11,1 por 100 . Por si fuera poco se han abierto consultas respecto a temas nuevos como son comercio y medio ambiente, comercio y tipos de cambio, seguridad alimentaria y comercio y energía. Los países desarrollados de la OMC siguen, además, avanzando en sus discusiones respecto a los denominados temas de Singapur excluidos de la Agenda de Desarrollo de Doha (contratación pública, inversiones y competencia). A falta de un acuerdo global basado en la regla del compromiso único (single undertaking) la UE está buscando «cosecha temprana» (early harvest) de acuerdos en facilitación del comercio, barreras técnicas y agilización del mecanismo de solución de diferencias. 
sanciones rusas si culminaba tal firma. La UE ha avanzado también con algunos acuerdos de Partenariado de la UE con los países del Grupo África-Caribe Pacífico cubierto por el Acuerdo de Cotonou (países ACP).

El Secretariado de la Asociación de Naciones de Asia Oriental (ASEAN) ha proseguido las negociaciones para el proyecto de la Asean Economic Community para 2015. Venezuela ha ido normalizando su incorporación al Mercosur tras su controvertido ingreso en 2012 aprovechando la suspensión temporal de la membresía de Paraguay que vetaba tal ingreso.

La República Dominicana se ha incorporado al Sistema de Integración Centroamericana (SICA) como octavo miembro.

En el área del Pacífico cabe señalar que la rutinaria cumbre del Asia-Pacific Economic Forum (APEC) continúa avanzando con ideas sobre facilitación de comercio, mientras que la ASEAN decidió aceptar para 2015 la solicitud de Timor Oriental de convertirse en su undécimo Estado miembro tras la retirada definitiva de las fuerzas de la ONU de su territorio.

En el otro extremo del Pacífico, Perú, Chile, Colombia y México van consolidando su Alianza del Pacífico con su VII Cumbre celebrada en Lima, quedando pendiente el ingreso en ella de Costa Rica y posiblemente de Panamá.

En el plano comercial, a finales de 2013 quedan encima de la mesa dos macronegociaciones que, de llegar a culminar, modificarán profundamente el comercio mundial: el Transpacific Partnership (TPP) (Dadusch, 2013) que incluye doce países asiáticos y Estados Unidos a los que Japón ha expresado su deseo de integrarse (13 de marzo) y, sobre todo, la Transatlantic Trade and Investment Partnership (TTIP) cuya negociación se inició el 5 de julio pero que quedó temporalmente paralizada hasta su reanudación unas semanas más tarde por la crisis del espionaje norteamericano a las comunicaciones de líderes europeos.

Y queda también, para acabar este apartado, el tema del comercio ilícito de productos falsifica- dos (artículos de lujo, DVD, medicamentos, etcétera) que no hay manera de cortar pese a que países como China no pusieron ningún reparo en aceptar el Acuerdo sobre Aspectos de los Derechos de Propiedad Intelectual relacionados con el Comercio (TRIPS o ADPIC) cuando entraron en la OMC. La muerte de 300.000 chinos por la ingestión de medicamentos falsificados ha puesto un toque de alarma sobre este comercio internacional ilícito que parece ha superado al tráfico internacional ilegal de drogas.

\section{El Sistema Monetario Internacional y el papel del FMI}

El Sistema Monetario Internacional no ha registrado sacudidas importante en 2013, como lo hizo en 2012, debido a las serias advertencias de China y Japón a Estados Unidos (17 de octubre) de que no seguirían comprando deuda norteamericana y que abandonarían el dólar a su suerte si los Estados Unidos no eran capaces de asegurar el cobro del servicio de la deuda cada vez que se asiste a un bloqueo fiscal por la negativa del Congreso a aumentar el techo de déficit al que debe aspirar la Administración Obama para hacer frente a sus gastos. Esta presión ha sido determinante en todo momento para que la Administración norteamericana y la Reserva Federal trataran de evitar el desastre que supondría que los principales tenedores de deuda americana cumplieran su amenaza y hasta que el yuan se refuerce por los avances de la economía china en congruencia con el nuevo programa económico chino de reforzar el consumo interno y no depender tanto de las exportaciones. Por otra parte, los chinos están liberalizando los controles sobre el uso del yuan para operaciones comerciales que se pueden negociar en Londres y Singapur al tiempo que, en octubre, el Banco del Pueblo de China acordó un swap de divisas con el BCE por un importe de 350.000 millones de yuans (42,111 millones de euros). 
El euro, con una zona euro reforzada por el ingreso de Letonia el 1 de enero de 2014 y la actuación decidida de la troika (Comisión Europea, Banco Central Europeo y Fondo Monetario Internacional) para evitar su rotura ${ }^{4}$, se ha sobrepuesto a los muy malos momentos que afrontó en 2012 con Grecia, Portugal, Irlanda y Chipre en situación de rescate y España en situación de rescate bancario.

Ante la lenta marcha de la economía norteamericana y los temores de poco crecimiento, la Reserva Federal norteamericana (FED) decidió continuar con la operación de inyección de liquidez de 267.000 millones de dólares, lanzada a mediados de 2012, y un anuncio de compra de 40.000 millones de activos hipotecarios y de 45.000 cada mes hasta que la tasa de desempleo americana baje al 6,5 por 100, en la que ha sido la primera vez que la FED se ha planteado objetivos no monetarios sino de empleo en sus cien años de existencia. Las mejores perspectivas económicas y monetarias en Estados Unidos han servido para que, antes de dejar la presidencia de la FED, Bernanke haya decidido, a finales de año, un primer recorte en estas ayudas monetarias expansivas.

Durante el 2013 ha seguido el aumento en la acumulación de deuda pública por casi todos los grandes países. Los altos niveles de deuda pú-

\footnotetext{
4 La zona euro comprende, a 1 de enero de 2014, 18 de los 28 Estados miembros de la UE: Alemania, Austria, Belgica, España, Finlandia, Francia, Irlanda, Italia, Luxemburgo, Holanda y Portugal desde 1999; Grecia desde 2001; Eslovenia desde 2007; Chipre y Malta desde 2008 , Eslovaquia desde 2009, Estonia desde 2011 y Letonia desde su ingreso el 1 de enero de 2014, con un tipo de cambio fijado en 0,70804 lati por cada euro sólo unos pocos años después de que Letonia tuviera que ser rescatada por el FMI con 7.500 millones de euros que ha podido devolver gracias a un duro programa de ajuste fiscal. La eurozona tiene, tras este último ingreso de Letonia, un total de 315 millones de europeos compartiendo la moneda común. A partir del 1 de febrero de 2014 Andorra tiene autorización para emitir su propia moneda en euros. En iguales términos que Mónaco, San Marino y el Vaticano. La crisis económica presente -con la paralela reducción de ingresos fiscales- ha hecho que, en la actualidad, la mayoría de los países de la eurozona no cumpla con los criterios de déficit fiscal (hasta 3 por 100 del PIB) y deuda pública viva (hasta 60 por 100 del PIB) marcados por el Tratado de Mastricht de 1992, por el Pacto de Estabilidad y Crecimiento de 1997 y por el Tratado Europeo de Estabilidad, Coordinación y Gobernanza de 2012 (fiscal Compact) finalmente aceptado por 26 de los 28 Estados miembros (todos menos Gran Bretaña y la República Checa).
}

blica y privada acumulados no han hecho que la financiación internacional desapareciera y hasta las primas de riesgo de los países más vulnerables, que a comienzos de 2013 partieron de unos niveles altísimos de coste para su deuda (de 1016 para Grecia, 462 para Portugal, 330 para España y 254 para Italia) y que sufrieron luego oscilaciones al alza, se han relajado pese a que casi todo el mundo considera casi imposible que los créditos hoy vivos puedan llegar a amortizarse sin quitas considerables.

En el FMI se ha seguido luchando para conseguir culminar el proceso de ratificación del paquete de reformas, con su $14^{\mathrm{a}}$ revisión general de cuotas y de gobernanza que se adoptó el 15 de diciembre de 2010 y que va a permitir pasar de unos recursos actuales de unos 625.000 millones de DEG (cuotas 238.000, Nuevo Acuerdo de Préstamos 370.000 y Acuerdo General de Préstamos 20.000) a casi 1 billón de DEG con duplicación de recursos y reajustes del 6 por 100 para dar más poder de voto a varios países emergentes. De momento el billón de capacidad de préstamo del FMI se ha alcanzado gracias a los últimos préstamos acordados dentro del nuevo Acuerdo de Préstamos por varios países y que quedarán absorbidos por las cuotas cuando se materialice la $14^{\mathrm{a}}$ revisión general de cuotas.

Pese a que todavía no ha llegado a consensuarse una nueva fórmula para la determinación de cuotas futuras en el FMI, ya se ha realizado una serie de ajustes, quitando poder a los países europeos sobrerrepresentados y dando más poder a los países emergentes hasta ahora infrarrepresentados.

En esta etapa el FMI -que durante años languideció- ha recibido un claro soporte del G20 para asegurar la supervisión que, si bien iba realizando, tenía más un carácter nacional que sistémico y de tipos de cambio entre las divisas, como ocurre de acuerdo con la decisión de supervisión integrada que ha substituido a la anterior de 2007.

Continuando con la acción de apoyo al euro, iniciada en 2012 el FMI, ha seguido implicado $\triangle$ 
en el seguimiento de los planes de rescate de Grecia, Irlanda, Chipre y Portugal, habiendo dada por finalizada su misión en Irlanda para principios de 2014 por considerar que Dublín podrá seguir financiándose normalmente en los mercados.

EI FMI va siguiendo con la dolorosa aplicación de condicionalidades para superar las crisis griega y potuguesa y para culminar el rescate pactado para la crisis de Chipre (15 de marzo) en que por primera vez los accionistas y los cuenta-corrientistas que tenían depósitos superiores a 100.000 euros en los bancos se ven afectados para pagar 5.800 euros del rescate total de 10.000 , asociado al cierre del banco Laiki con la correspondiente transferencia de sus deudas contraídas con el Banco Central Europeo al Banco de Chipre.

Para acabar con este capítulo monetario-financiero resulta interesante destacar que el G20 y la OCDE han seguido con su lucha contra los paraísos fiscales ante la evidencia de que las grandes corporaciones mundiales, con filiales en diferentes países con baja fiscalidad o en paraísos fiscales, no pagan un nivel de impuestos adaptado a su nivel de actividad en cada uno de ellos. Este fue tema estrella en la reunión en la Cumbre del G8 en Long Erne, bajo presidencia inglesa.

Por otra parte, y tras la denuncia del Banco de Pagos Internacionales, dirigido por Jaime Caruana, de que los bancos deben sobreponerse a su desconfianza recíproca (23 de abril), los criterios de solvencia del Comité de Supervisión Bancaria de Basilea (Basilea III) se han visto reforzados en un movimiento que no ha gustado a los bancos norteamericanos.

Al FMI le queda por hacer muchos deberes en los próximos tiempos para deshacerse de su imagen de austeridad, sobre todo tras ponerse en duda que los multiplicadores keynesianos sean mayores a los antes estudiados (Blanchard, 2013) y de querer imponer ajustes fiscales a toda costa, de tirar adelante su supervisión global y de finalizar la cuestión de aumento de cuotas y cambio en su gobernanza, con mayor peso de los países emergentes en su Directorio.

\section{La cooperación al desarrollo y los Objetivos del Milenio post 2015}

Cuando la Asamblea General de las Naciones Unidas de septiembre de 2000 aprobó los Ocho Objetivos del Milenio, después de un ciclo de grandes conferencias internacionales convocadas por Naciones Unidas en el decenio de los noventa del siglo pasado, se pretendía que para 2015 se hubieran reducido la pobreza extrema y la población en situación de hambre a la mitad de la existente en el 2000, que la educación alcanzara a ser universal, que se igualaran los sexos, que se redujera la mortalidad infantil, que mejorara la salud maternal y que se avanzara en la lucha contra el SIDA, la malaria y otras enfermedades transmisibles, así como que se asegurara un desarrollo sostenible y que se consiguiera un auténtico «partenariado» para el desarrollo, cambiando las reglas globales del juego comercial, financiero, de deuda y aumentando los flujos de ayuda desde los países ricos a los pobres así como la transferencia de tecnología y los flujos de inversión privada. Estos propósitos se vieron reforzados por el Consenso de Monterrey adoptado por la Conferencia de las Naciones Unidas sobre Financiación del Desarrollo de 2002 en donde, como viene siendo el objetivo normal desde el primer decenio de las Naciones Unidas para el Desarrollo 1960-1970, se decía que los países donantes deberían ir avanzando hacia una transferencia hacia los países pobres de un 0,7 por 100 de su PIB.

Algunos de aquellos objetivos fijados en el año 2000 ya se han conseguido en muchos países. La pobreza absoluta, que en el 2000 se estimaba alcanzaba al 47 por 100 de la humanidad, se sitúa ahora en poco más del 20 por 100, gracias, sobre todo, a los procesos de desarrollo en ciertos países emergentes. El acceso de la población al abastecimiento de agua potable ha avanzado mas rápidamente de lo que se había previsto y solamente algunos países del África Subsahariana están por detrás de los avances $\triangleright$ 
medios registrados en los siete objetivos de carácter nacional. En lo que se refiere al $8^{\circ}$ objetivo, el de la asociación global a favor del desarrollo, los resultados han sido desiguales como consecuencia, en parte, del cambio de situación internacional en que hoy nos movemos en relación a la que nos movíamos en el año 2000. La Agenda de Desarrollo de la Ronda de Doha de la OMC ha avanzado poco. Los flujos de Ayuda Oficial al Desarrollo se han estancado e incluso han retrocedido como consecuencia de los problemas fiscales en los que muchos países desarrollados están inmersos, y ya casi nadie habla de avances cuantitativos en la cooperación al desarrollo sino avances cualitativos referidos a la eficacia de la ayuda, la coordinación de donantes, la apropiación por parte de los beneficiarios de la asistencia y una mayor participación de los mismos en la gobernanza de los órganos e instituciones de cooperación.

De hecho, la ayuda oficial al desarrollo (AOD) ya no es el principal flujo de recursos de los países ricos a los pobres pues las inversiones internacionales y las remesas de emigrantes le han pasado por delante, si bien ambos flujos tienen sus pros y sus contras en relación a la AOD.

Al mismo tiempo, ya no son solamente los países ricos del Comité de Ayuda al Desarrollo de la OCDE los que llevan a cabo acciones de ayuda, sino que una serie de países de renta media, y sobre todo China, están llevando a cabo la cooperación al desarrollo en muchos países subdesarrollados. Pese a ello, la UE y sus Estados miembros siguen haciendo más de la mitad de la AOD y siguen estando a la cabeza de las orientaciones que se siguen en la cooperación internacional (Comisión Europea, 2013).

El presidente del Grupo del Banco Mundial (el coreano nacionalizado norteamericano Jim Yong King) ha impulsado el proceso de ratificación del primer aumento de capital del BM en 20 años, ha impulsado que en la Reunión de Moscú se avanzara hacia la $17^{\text {a }}$ Reposición de recursos de la Asociación Internacional de Fomento (AID) y ha seguido batallando para que la Corporación Financiera Internacional (CFI) estimule a los países en desarrollo para que hagan desaparecer las incertidumbres y los obstáculos que hacen difícil que las empresas internacionales inviertan en su suelo y a que la Agencia Multilateral de Garantía de Inversiones (MIGA) no solo asegure los flujos de inversión del Norte hacia el Sur sino también los crecientes flujos Sur-Sur.

Con todo este panorama cambiado respecto a los parámetros en que se desarrollaba la cooperación al desarrollo en 2000, el Grupo de Alto Nivel creado por Ban Ki-moon reunido en Bali (25-27 de marzo), la quinta conferencia para el desarrollo de África celebrada en Tokio (1-3 de junio), la reunión del Global Forum para el desarrollo de la OCDE (4-5 de abril) y los European Development Days de la UE (26-27 de noviembre), así como una serie de otras reuniones, están avanzando en el estudio de objetivos cifrados para el post 2015 así como respecto a innovaciones para conseguir nuevas acciones para la reducción de la pobreza con mejora en la cohesión social y lucha contra la corrupción y acciones de buen gobierno y mejora del medio ambiente.

Los problemas del desequilibrio monetario internacional han hecho perder un cierto interés sistémico a la cooperación al desarrollo para dejar paso a cuestiones tales como qué es lo que va a hacerse tras el 2015 para establecer unos nuevos Objetivos de Desarrollo del Milenio ( $4^{\circ}$ World Forum de la OCDE: Beyond 2015; the future of Development Goals) o qué debe hacerse en la lucha contra la corrupción y a favor de la buena gobernanza o la conexión entre el desarrollo y el medio ambiente.

Estamos, pues, en una fase de redefinición de la Agenda para el Desarrollo que, partiendo de las experiencias acumuladas y vistas sus carencias, permita avanzar por vías de desarrollo sostenible y que teniendo en cuenta las nuevas correlaciones de fuerzas en el mundo permitan luchar contra la pobreza respecto a la generación actual y respecto a futuras generaciones. 


\section{La Unión Europea y su zona euro}

El 2013, bajo las presidencias del Consejo de Irlanda -en el primer semestre- y de Lituania -en el segundo- ha aportado a la integración europea y a su zona euro elementos positivos y negativos. Un elemento negativo fue la falta de decisiones importantes en el proceso integrador, por el frenazo impuesto por Alemania, antes de sus elecciones legislativas de octubre, por miedo a que si aceptaba demasiada solidaridad con los países en crisis, el Gobierno de Angela Merkel podía caer. Ello generó muchas vacilaciones en el proceso europeo hasta final de año en que se perfiló el Gobierno de Gran Coalición que permitió la reelección de Angela Merkel como canciller.

Positivo ha sido para la UE, por ejemplo, el haberse ampliado con el ingreso de Croacia, el 1 de julio de 2013 , como su $28^{\circ}$ miembro y positivo ha sido que la Comisión Europea recomendara el 3 de junio que Letonia pudiera entrar en la zona euro como su $18^{\circ}$ miembro a partir de enero de 2014, en una recomendación que el Consejo aprobó y que permite que, desde enero de 2014, el lati pase a la historia.

Positivas han sido la continuación de las negociaciones de ampliación con Turquía tras una forzada interrupción por los problemas políticos del Gobierno islamista moderado de Erdogan y la decisión de avanzar en la negociación de adhesión con Serbia como compensación a que Belgrado aceptara una negociación entre la UE y Kosovo. El nuevo Gobierno de Islandia formado tras las elecciones de abril, por el contrario, decidió retirar (12 de septiembre) la candidatura de adhesión que había presentado en julio de 2009 en un momento en que la UE había sido percibida como una tabla de salvación respecto al shock financiero en que Islandia había caído.

Al margen de estas circunstancias, la UE ha presenciado en 2013 luchas en varios frentes que, aunque han acabado -en la mayoría de los casos- con una solución satisfactoria, han dado lugar a una serie de tiras y aflojas que han hecho pensar a los observadores poco avisados que el movimiento integrador estaba atravesando por un mal momento. Seguramente el anuncio del premier británico (presionado por el ala antieuropea de su partido conservador) de que piensa convocar un referéndum sobre la permanencia de Gran Bretaña en la UE en 2017, si es reelegido en las elecciones que tendrán lugar después del referéndum de independencia de Escocia, habrá contribuido a esta idea de que la UE no va bien. El Consejo Europeo de Relaciones Exteriores ponía de manifiesto el choque entre las democracias del norte y el sur de Europa que parece haber substituido al tradicional choque ComisiónEstados miembros (CERE, 2013).

El primero de los problemas que la UE ha tenido que afrontar ha sido el de la aprobación del Marco Financiero Plurianual 2014-2020. Después de muchos tiras y aflojas los países que no querían que el presupuesto anual de la UE excediera del 1 por 100 de la Renta Nacional Neta de los Estados miembros se ha impuesto. De hecho, la propuesta de la Comisión formulada en 2012 no tuvo demasiadas ambiciones y, luego, la discusión en el Consejo y el Trílogo con el Parlamento Europeo no han añadido gran cosa a un presupuesto a todas luces insuficiente para permitir relanzar la economía de la Unión -en horas bajas pese a haber salido de la recesión de dos años a partir del segundo trimestre- y hacer frente a los desajustes de los países mas débiles del conjunto europeo y, en especial, de la zona euro. El hecho de que la Comisión Europea y el Parlamento no hayan insistido en incluir el Fondo Europeo de Desarrollo destinado a los Países de África, Caribe y Pacífico (ACP) en el Marco Financiero Plurianual, como habían reivindicado en el pasado, es consecuencia del deseo de preservar, al menos, la contribución adicional de los 30.000 millones de euros con la que se dota el undécimo FED para el periodo 2014-2020. El desbloqueo del Marco Financiero Plurianual 20142020 y del presupuesto para 2014 ha permitido tirar adelante la reforma de los reglamentos de la $\triangle$ 
Política Agraria Común y de la Politica Regional y de Cohesión dando, además, entrada a nuevas líneas para fomentar el empleo de los jóvenes y hacer posible algunas acciones que favorezcan la estrategia 2020 para hacer una Europa más competitiva y justa.

La UE ha continuado con su política comercial común con los acuerdos comerciales y de asociación firmados, o entrados en vigor en 2013 , a los que se hizo referencia en el apartado 2 referido al comercio internacional, con la perspectiva, además, de un futuro gran acuerdo de libre comercio con los Estados Unidos (Trans Atlantic Trade and Investment Partnership) que alteraría grandemente los parámetros en los que se ha venido moviendo el sistema multilateral de comercio.

El periplo de la UE durante 2013 ha venido connotado por la continuación de las operaciones de rescate a los países periféricos con dificultades para acceder a los mercados financieros sin pagar unas primas de riesgo muy altas, $y$ para ir acordando nuevas piezas para la construcción de la Unión Económica y Monetaria que no fue capaz de crear el Tratado de Maastricht y que tampoco creó el Tratado de Lisboa, que solamente establecieron una unión monetaria con su correspondiente moneda común (Sanchis, 2013).

Con respecto a las operaciones de rescate, la UE puede mostrarse satisfecha por haber evitado la salida de la eurozona de Grecia, Portugal, Irlanda y Chipre, con paquetes de intervenciones y condicionalidades en que la Comisión Europea ha actuado conjuntamente con el Banco Central Europeo y el Fondo Monetario Internacional (actuando como troika). Imponiendo, en todo caso, políticas de consolidación fiscal que no han ayudado al crecimiento y que han generado protestas de los grupos sociales que han visto reducido su nivel de vida como consecuencia de los recortes de gasto público y que han creado nuevas insatisfacciones por las modificaciones en las legislaciones laboral y fiscal. De todas formas, las políticas así impulsadas han servido para que Irlanda salga del rescate y vuelva a poder finan- ciarse en los mercados privados a partir de enero de 2014 y ha servido, también, para que España no haya tenido que solicitar rescate-país y que la troika haya decidido que el sistema bancario español no necesitará apoyo adicional europeo desde inicios de 2014 para superar su crisis.

El Banco Central Europeo ha seguido teniendo un papel relevante respecto a los rescates pese a las críticas que su presidente Mario Draghi ha recibido de Alemania por sus compras masivas de deuda y al reducir dos veces los tipos de interés de la eurozona para impulsar la economía. Así, el tipo de interés fue rebajado del 0,75 al 0,50 por 100 el 2 de mayo y al 0,25 por 100 el 7 de noviembre por temor a la deflación. EI BCE ha seguido financiando a los bancos privados $y$ estos han comprado deuda pública con el correspondiente diferencial de beneficio.

En relación a los nuevos elementos que permitan avanzar hacia la Unión Económica y Monetaria, y tras la puesta en marcha a finales de 2012 del Mecanismo Europeo de Estabilidad (MEDE) como cortafuegos permanente para asumir rescates con sede en Luxemburgo, el 2013 ha visto avances en la instrumentación de la Unión Bancaria. El 15 de noviembre se aprobó el establecimiento del supervisor bancario único que empezará a actuar con el BCE a finales de 2014, una vez se hayan hecho las verificaciones de solvencia, a nivel nacional, de los bancos sistémicos a principios de 2014. El BCE ha empezado desde fines de 2013 a reclutar el personal que llevará a cabo la supervisión única de los bancos europeos de carácter sistémico desde finales de 2014.

A finales del año 2013 se ha llegado también a un difícil principio de acuerdo para el establecimiento de un Mecanismo Único de Resolución Bancaria sin que, por el momento, se haya transferido a la Comisión la potestad de decidir si un banco debe cesar de operar, pues tal decisión se la siguen reservando los Estados miembros. Tampoco se ha llegado a establecer ningún fondo común de resolución por temerse que ello diera lugar a transferencias hacia los países con bancos $D$ 
más vulnerables en contraposición a lo que estipulan los tratados. El tema de un fondo común de garantía de depósitos ha quedado también aplazado, si bien la directiva de la garantía de depósitos hasta 100.000 euros por parte de las autoridades nacionales tiene ya el visto bueno del Parlamento Europeo.

Habrá que ver si los análisis de solvencia de las autoridades nacionales -antes de ceder la competencia de supervisión única al Banco Central Europeo- tienen más éxito que los análisis sobre solvencia llevados a cabo por la Agencia Bancaria Europea (una de las tres agencias creadas el 1 de enero de 2011: Agencia Bancaria Europea, Comité Europeo de Valores y Comité Europeo de Supervisores de Seguros y Fondos de Pensiones) que no lograron restablecer la confianza mutua entre las instituciones financieras cara al funcionamiento de un mercado único bancario.

El 2013 acaba con una relajación de las primas de riesgo de los países vulnerables y con perspectivas de recuperación moderada de la economía europea lo cual debe moderar, también, el debate ideológico entre quienes atacan a la UE por seguir con las políticas de austeridad, de consolidación fiscal y de avance en las reformas estructurales pendientes, defendidas por la troika como las únicas posibles, y quienes creen que la EU debería ser mas activa en relanzar la economía europea y no solo conformarse con contemplar el aumento del capital del Banco Europeo de Inversiones ya acordado en 2012 o las medidas monetarias no convencionales del BCE (Think Tank 20, 2013).

La Comisión Europea ha ganado capacidad de acción económica y de control sobre los presupuestos nacionales de los 28 Estados miembros, por primera vez, en 2013 y esto es positivo para evitar futuras crisis pero, de momento, la unión fiscal y la unión política hacia las que debería avanzar la UE de acuerdo con las máximas autoridades comunitarias (Van Rompuy et al., 2011) no avanza por mucho que 11 Estados miembros hayan aceptado el principio de una tasa sobre las transacciones financieras que en el futuro podría contribuir al presupuesto general de la UE.

La sustitución de Junker por el holandés Jeoren Dijsselbloen en la presidencia del Eurogrupo consolida, en el plano monetario, la Europa a dos velocidades, pues las decisiones adoptadas en el Eurogrupo a 18 tienen un carácter ambiguo respecto a lo que se diga en el ECOFIN a 28 sobre el acquis comunitario y lo mismo sucede con las decisiones del Banco Central Europeo y del Sistema Europeo de Bancos Centrales.

En este año también, como ya sucediera en el anterior, la escasa entidad de Irlanda y Lituania como países que han ostentado la presidencia rotatoria del Consejo ha permitido el reforzamiento de la figura de Herman Van Rompuy como presidente del Consejo Europeo y ha dado protagonismo a la canciller alemana Angela Merkel preocupada por su reelección en octubre y por no modificar los tratados en un sentido que obligara a Alemania a ser mas solidaria respecto a los países periféricos en mayor medida de lo que ya es.

La alta representante y vicepresidenta de la Comisión, la baronesa Catherine Ashton, que parecía haber jugado bien las cartas de su Servicio Europeo de Acción Exterior en la crisis de Irán y que en el Consejo Europeo del 19-20 de diciembre había impulsado avances respecto a la Política Europea de Defensa, ha visto como Putin le ha ganado la partida de la influencia sobre Ucrania. De todas formas, la puesta en marcha del Servicio Europeo de Acción Exterior que dirige la baronesa Ashton está creando muchas críticas en el análisis de las relaciones exteriores de la UE por las duplicidades de actuación entre las direcciones generales de la Comisión Europea que el SEAE genera y por las tensiones que se manifiestan entre diplomáticos nacionales adscritos temporalmente a la SEAE y los funcionarios permanentes de la Comisión Europea y el Consejo.

Desde enero de 2014 la Comisión va a disponer de los nuevos instrumentos de acción exterior aprobados en el Consejo en los últimos meses $\triangleright$ 
de 2013: nuevo instrumento de cooperación al desarrollo, nuevo FED, nueva decisión sobre los países y territorios de ultramar dependientes de los países miembros, nueva política de vecindad, etcétera.

\section{España y el sistema económico internacional}

A lo largo de 2013 la economía española ha registrado una contracción del 0,3 por 100 con una inflación del 0,9 por 100 y un déficit presupuestario del 6,8 por 100 , al tiempo que el nivel de desempleo se sitúa algo por encima del 25 por 100.

Por ello no puede decirse que la economía española esté recuperada del colapso derivado del estallido de la burbuja inmobiliaria y de la crisis mundial, pues con un endeudamiento público que ha llegado a casi el 100 por 100 del PIB, un alto endeudamiento privado y la necesidad de seguir absorbiendo activos bancarios dañados a través del Banco Malo (Sociedad de Gestión de Activos procedentes del Reestructuración Bancaria: SAREB), la troika sigue insistiendo en que el Gobierno de Mariano Rajoy va en la buena dirección, si bien debe seguir con reformas estructurales para cumplir con la condicionalidad restrictiva aceptada por el Gobierno en su diálogo con las instituciones europeas para negociar el $\mathrm{Me}$ morando de Entendimiento (MoU) sobre las condiciones de la política económica pese a no haber llegado a solicitar el rescate-país que durante 2012 pareció inminente: reforma administrativa, reforma del sistema de pensiones, reforma fiscal, reforma laboral (Capaldo y Izurieta, 2013).

La economía española salió de la recesión en el tercer semestre de 2013 y presenta cara al 2014 mejores perspectivas pese a que las pymes se quejan de que no les llega el crédito y a que muchas familias ven recortados sus presupuestos. La economía crecerá, aunque raquíticamen- te, las exportaciones ${ }^{5}$ y el turismo van muy bien y la prima de riesgo española ha descendido, a finales del 2013, hasta un nivel cerrcano a los 200 puntos básicos, cuando a principios de año estaba a 358 puntos básicos (era de 650 a mediados de 2012 cuando todo apuntaba a que debería solicitarse un rescate para obtener fondos mas baratos del FMI y de las instituciones europeas, cosa que finalmente no se hizo).

La Bolsa se ha recuperado a lo largo del 2013 en un 21 por 100, llevando al IBEX hasta casi los 10.000 puntos, lo cual constituye la evolución europea más brillante, solo detrás de la Bolsa alemana como consecuencia del buen comportamiento de los bancos gracias, sobre todo, a su actividad internacional y a la operativa de recibir fondos baratos del BCE y adquirir deuda pública mejor retribuida.

La troika decidió en diciembre que daba por cerrado para España el rescate bancario a partir de enero de 2014, tras no utilizarse más que 41.300 millones de euros de los 100.000 que la Facilidad Europea de Estabilidad Financiera puso al servicio del Fondo de Reestructuración Ordenada Bancaria (FROB), en junio de 2012, para ayudar a la recapitalización y reestructuración de los bancos españoles de acuerdo a unos tipos de interés muy inferiores a los que las instituciones españolas nacionalizadas o ayudadas podían obtener en aquellos momentos en los mercados financieros.

En concordancia con estas recomendaciones y con su propia ideología política, el Gobierno de Mariano Rajoy ha tratado de reducir los déficits fiscales con el trasfondo de la Ley de Estabilidad $\square$

\footnotetext{
5 La exportación española supone en 2013 el 34 por 100 del PIB (en 1962 representaba el 8 por 100) contra el 58 por 100 que representa el consumo interno. Este porcentaje exportador es superior al de Francia (27 por 100), Italia (30 por 100) y Gran Bretaña (31 por $100)$ y sólo superado en Europa por Alemania (52 por 100) que aceleró su capacidad exportadora tras su ajuste 2003/2006. En España hay 115.000 empresas exportadores (un 10 por 100 más que en 2012). España no ha perdido demasiada cuota de mercado mundial como sí lo han hecho otros países europeos debido al empuje de los países emergentes. En 2002 España suponía el 2,30 por 100 de las exportaciones mundiales y en 2012 esta cifra se había reducido al 1,90 por 100. Entre ambas fechas las reducciones de otras países europeos fueron mayores: Italia del 3,90 al 2,70; Francia del 4,90 al 3,40 ; Reino Unido del 5,20 al 3,40 y Alemania del 8,90 al 7,90 .
} 
Presupuestaria. Esto ha sido alabado por el FMI, la OCDE, la troika y la misma Comisión Europea en el nuevo procedimiento de análisis presupuestario (Six Pack y Two Pack), pero la forzada reducción de gastos en sanidad, en educación y en otros sectores sociales para cumplir los objetivos de déficit fijados por Bruselas han dado lugar a un amplio descontento social y de los Gobiernos de las comunidades autónomas que han acusado al Gobierno central de aplicar asimétricamente las tolerancias ampliadas de déficit aceptadas para España (28 de mayo) por la Comisión Europea. El caso de Cataluña es quizás, en este contexto, el más evidente por la presión que la Generalitat está ejerciendo a favor de la «libertad de elegir» y a favor de la creación de un «Estado propio» (Vía catalana a la independencia del 11 de septiembre).

España ha sido bien tratada por la troika en relación a su déficit fiscal, sin llegar, además, a abrir un expediente sancionador por desequilibrio presupuestario excesivo. En lo que sí han insistido la Comisión Europea y el BCE, como antes se apuntaba, es que España debe vigilar más los desequilibrios que presenta y acometer las reformas estructurales pendientes.

En cuanto a sus relaciones con el resto del mundo, España ha luchado para no salir damnificada en la reforma de la Política Agraria Común y de la Politica Regional y de Cohesión realizadas, una vez aprobado el Marco Financierro Plurianual Europeo 2014-2020, así como de llevarse la mayor contribución del nuevo fondo contra el paro juvenil establecido en el nuevo Marco.

En el plano multilateral, España ha lanzado su candidatura para obtener uno de los puestos no permanentes en el Consejo de Seguridad de las Naciones Unidas para 2015-2016, aunque va a tener que superar el handicap que representa el haber reducido significativamente su volumen de ayuda al desarrollo (Olivié, 2013), haber disminuido su interés por la Alianza de Civilizaciones, estar de nuevo relativamente enemistada con Gran Bretaña por la cuestión de Gibraltar y haber perdido una parte del liderazgo que había tenido respecto a Latinoamérica antes de que la Cumbre Iberoamericana de 18-19 de octubre en Panamá (la primera sin presencia del Rey por enfermedad, substituido por el Príncipe y la última con Enrique Iglesias al frente de la Secretaría Iberoamericana) hiciera palpable lo contrario, tras lo que ya se había apuntado con algunas nacionalizaciones sufridas por multinacionales españolas en ciertos países sudamericanos o en la controversia sobre la continuidad de las obras de la ampliación del Canal de Panamá por el consorcio liderado por SACYR (Palacio y Aybar, 2013).

Tampoco resulta positivo que España haya bajado del puesto 30 al 40 en el ranking de transparencia y corrupción de Transparency Internacional y que Madrid no consiguiera los apoyos suficientes para ser la sede de los Juegos Olímpicos 2020 que, finalmente, se adjudicaron a Tokyo y que los inversores internacionales denuncien que entre 1978 y 2011 el Gobierno central y las comunidades autónomas hayan puesto en vigor 230.000 normas, lo que crea dificultades para la implantación y el funcionamiento de las empresas (Granell, 2013) lo cual ha hecho caer a España hasta el puesto 52 (antes estaba en el 46) en el Doing Business World Bank Survey y ha hecho que España esté en el puesto 142 en cuanto al ranking de facilidad para iniciar nuevos negocios.

Un consuelo, quizás menor, pero consuelo al fin, es que la española Arancha González ha sido designada nueva directora del Centro de Comercio Internacional UNCTAD/OMC por el secretario general de las Naciones Unidas, nombramiento éste que, sin el relieve del de Joan Clos al frente de Habitat o el de Caruana al frente del Banco de Pagos Internacionales, sirve para poner de relieve que algunos españoles ocupan cargos relevantes en el sistema internacional.

\section{Bibliografía}

[1] ÁlVAREZ, I.; LUENGO, F. y UXO,J.(2013): Fracturas y crisis en Europa, Madrid, Clave Intelectual, EUDEBA. 
[2] AYLLON, B. y OJEDA,T. (Coordinadores) (2013): La Cooperación Sur-Sur y Triangular en América Latina, Madrid, Catarata para el IUDC.

[3] BADIE, B. (2013): La diplomacia del contubernio: los desvíos oligárquicos del Sistema Internacional, Buenos Aires, EDUNTREF.

[4] BLANCHARD, O. y LEIGH, L.(2013): «Growth Forecast errors and fiscal multipliers", IMF Working Papers, $n^{\circ} 13 / 1$.

[5] BORRELL, J. (2013): Europa, América Latina y la regionalización del Mundo, Madrid, IELAT.

[6] BRICALL, J.M. (2013): «Cinco ensayos sobre la crisis», Barcelona, RBA.

[7] BUSH, R. (ed). (2013): «Turmoil in North Africa", Review of African Political Economy, agosto.

[8] CAPALDO, J. y IZURIETA, A. (2013): «The imprudence of labour market flexibilization in a fiscally austere World", Genève, Internacional Labour Review, vol. 152, $\mathrm{n}^{\circ}$ 3, pp 1-26.

[9] COMISIÓN EUROPEA (2013): Development and External Assistance Policies, doc COM (2013)594 final, Bruselas.

[10] CONSEJO EUROPEO DE RELACIONES EXTERIORES (Leonard, M. (dir)) (2013): Choque de democracias del norte y sur de Europa, abril.

[11] CHEONG, I. (2013): «Negotiations for the Trans Pacific Partnership Agreement: Evaluation and implications for East Asian Regionalism», Tokyo, Asian Development Bank Working Paper series, $\mathrm{n}^{\circ} 428$, julio.

[12] DADUSH, U. (2013): «Política comercial fortuita». Estudios de Política Exterior $\mathrm{n}^{\circ}$ 153. Madrid,

[13] DE JUAN, A.; URIA, F.; BARRON, I. (2013): Anatomía de una crisis. Cómo la mala gestión y la injerencia política cambiaron la vida de todos y provocaron el rescate financiero, Barcelona, Deusto.

[14] DE LOMMBAERDE, P.H. y SODERBAUM, F. (eds) (2013): Regionalism, London, Sage para UNU-CRIS, 4 vols.

[15] EMMONT, S. (2013): Ten Billion, New York, Vintage.

[16] GANT, D.A. (2013): Liberalizing Internacional Trade alter Doha: multilateral, plurilateral, regional and unilateral Initiatives, Cambridge University Press.
[17] GARZÓN, A. (2013): La gran estafa, Barcelona, Destino.

[18] GRANELL, F. (2013): «Empresas multiregionales y Unidad de Mercado", La Vanguardia, Suplemento Negocios, 3 de febrero, pág. 10.

[19] GRANELL, F. (2013): «La Unión para el Mediterráneo como organismo internacional y como catalizadora de la cooperación europea», Revista de Derecho Comunitario Europeo, $\mathrm{n}^{\circ} 45$.

[20] LAMY, P. (2013): «The Future of Trade: The challenges of convergence» Report of the Panel on defining the future of Trade convened by WTO Director General Pascal Lamy, Geneva, 24 abril.

[21] MANCHESTER UNIVERSITY (2013): Aid for Trade in a World of global value chains: chain power, the distribution of rents and implications for the form of Aid.

[22] MORAVCSIK, A. (2013): «La UE y no China es la superpotenciadel futuro", El Confidencial, 19 de septiembre.

[23] MOYO, D. (2013): El ganador se queda con todo: la fiebre china por el control de los recursos naturals y lo que supone para el mundo, Barcelona, Galaxia Gutenberg.

[24] NIÑO BECERRA, S. (2013): Diario del Crash, Barcelona, Libros del Lince.

[25] OLIVIÉ, I. (2013): «¿Cumpleaños feliz? La Agencia Española de Cooperación Internacional para el Desarrollo celebra su 25 aniversario", Estudios de Política Exterior, $\mathrm{n}^{\circ} 156$. Madrid,

[26] PALACIO, V. y AYBAR, T. (eds) (2013): Cumbres Iberoamericanas; una mirada atrás, un nuevo rumbo, Madrid, Fundación Alternativas y Funglode.

[27] PIQUÉ, J. (2013): Cambio de era; un mundo en movimiento: de Norte a Sur, de Oeste a Este; Barcelona, Deusto.

[28] ROBINSON, A. (2013): Un reportero en la Montaña Mágica: cómo la élite de Davos hundió al Mundo, Barcelona, Ariel.

[29] ROCA, J. (Coord) (2013): La responsabilidad española en el calentamiento global, Madrid, Catarata. 
[30] RODRíGUEZ, M.(2013): Tratados de Libre Comercio en América del Sur: Tendencias, perspectivas y desafíos, Bogotá, CAF.

[31] SÁNCHEZ, C. (2013): España en BANKIArota, Málaga, SEPHA.

[32] SANCHIS, M. (2013): The Economics of the Monetary Union and the Eurozone Crisis, New York-Heidelberg, Springer.

[33] SKIDENSKY, R. (2013): El regreso de Keynes, Barcelona, Crítica.

[34] SUBRAMANIAN, A. y KESSLER, M. (2013): «The hyperglobalisation of Trade and its future», Global Future Foundation, Working Paper $\mathrm{n}^{\circ} 3$, junio.

[35] THE ECONOMIST (2013): El mundo en 2050: las tendencies que cambiarán el Planeta, Barcelona, Planeta.

[36] THINK TANK 20 (2013): The G20 and Central Banks in the New World of Unconventional
Monetary Policy, Washington, Brookings Institution.

[37] THORSTENSEN, V.; MACHADO, O. e IVAN.T. (organizadores), (2012): Os BRICS na OMC, Politicas comerciais de Brasil, Rusia, India, China e Africa do Sul, Brasilia, IPEA.

[38] TRIAS DE BES, F. (2013): El gran cambio, Madrid, Temas de hoy.

[39] UNCTAD (2013): Non Tariff Measures to Trade: Economic and Policy Issues for Developing Countries, Geneva.

[40] VAN GROASTEL, C. (2013): The Histoty and the future of the WTO, Geneva, WTO.

[41] VAN ROMPUY, H.; BARROSO, J.M.; JUNKER, J.C. y DRAGHI, M. (2012): Towards a genuine Economic and Monetary Union, Brussels, European Council.

[42] WAPSHOTT, N. (2013): Keynes vs. Hayek, Barcelona, Planeta Deusto. 
